\title{
Measurement of User Experience to Select a Comfortable Mattress
}

\author{
Jung-Yong Kim ${ }^{1}$, Seung-Nam Min ${ }^{1}$, Min-Ho Lee ${ }^{1}$, Joo-Hyun Jeong ${ }^{1}$, \\ Jung-Ho $\mathrm{An}^{2}$, and Young-Sung Shin ${ }^{2}$ \\ ${ }^{1}$ Department of Industrial \& Management Engineering, \\ Hanyang University, Ansan, Republic of Korea \\ jungkim@hanyang.ac.kr \\ ${ }^{2}$ Research Laboratory, Simmons Co. Ltd, Gyeonggi-do, Republic of Korea \\ cool821@simmons.co.kr
}

\begin{abstract}
This study was designed to develop a methodology measuring the user experience with mattress both in the past and showroom, and to eventually recommend a healthy and comfortable mattress for individual user. Five mattresses with different hardness were used to find the most compatible mattress with individual subject's physical and psychological condition. User experience such as lying on the mattress in showroom was analyzed by quantitatively measuring Electromyography of low back muscle, heart rate change, and oxygen saturation level. In addition, the whole body pressure distribution was measured to examine the dermal discomfort. A questionnaire was used to record the past personal experience and preference on mattress. A selection rule with the finally chosen four independent variables and mathematical scale was developed to find the best mattress for individual. Furthermore, a regression analysis was performed to predict the level of muscle relaxation in order to have the least measuring process in the showroom. The Body-Mattress Compatibility Score (BMCS) indicating the proper level of hardness was computed in this study and compared with subjective satisfaction score for validation, and it was found that ten out of twenty subjects showed the same score, and other ten subjects showed only one score difference.
\end{abstract}

Keywords: user experience, mattress selection, physical and psychological comfort, pressure distribution, body mattress compatibility, showroom.

\section{Introduction}

A sleep is one of the most important parts of daily life, we all know that the quantity and quality of sleep are greatly associated with the release of mental stress as well as physical fatigue. Therefore, a sufficient sleep and comfortable bed are very essential to maintain healthy physical and mental conditions [1].

In Korea, there are an increasing number of people using western style bed. However, they are often fastidious in choosing the right mattress for them. In fact, people use their past experience with their old mattress as well as the spontaneous experience they encounter in showroom to finally decide to buy a bed. People often lie down on 
the bed to examine how comfortable they are, and each individual makes a decision by using their own intuitive judgment. However, there is no warranty whether or not such decision could reflect their experience objectively and wisely.

Regarding the hardness of mattress, Suckling et al., (1957) reported that a hard mattress disturbed a sound sleep and made people toss and turn. Parson (1972) found that appropriate hardness of bed mattress was good for a sound sleep. Moreover, the hardness of mattress is associated with reducing the muscle pain [4].

$\mathrm{Yu}$ et al., (2009) used the level of physical relaxation of individual subject to evaluate different mattresses by monitoring psycho-physiological biofeedback. Yu (2010) reported that a biomechanical support from the hard mattress can make low back muscle relax. Lahm and Jaizzo (2002) observed that mattresses not supporting the upright spine did increase discomfort in the back and waist muscles.

Kim et al., (2007) reported that subjective comfort increased when skin pressure was equally distributed across mattress surface and skin temperature rise was minimal. Pressure concentration on a particular body part could cause a skin problem as well as increasing subjective discomfort [8]. The pressure distribution was described as one of the most important variables in designing comfortable mattress [2]. Also, it was reported that the pressure should be evenly distributed across major body parts (head, torso, waist and legs) so that the spine would not be overly bent or curved [4].

Therefore, the purpose of the study is to develop a methodology to measure user experience with mattress in the past and in the showroom as objectively as possible by using the multiple variables used in previous studies, in order to recommend a healthy and comfortable mattress for individual customer.

\section{Methodology}

In this study, it was a basic assumption that we would be able to find the most comfortable and healthy mattress for individual customers if we knew their previous experience as well as their physical and psychological experience in the showroom, possibly in a very quantitative manner (Fig. 1).

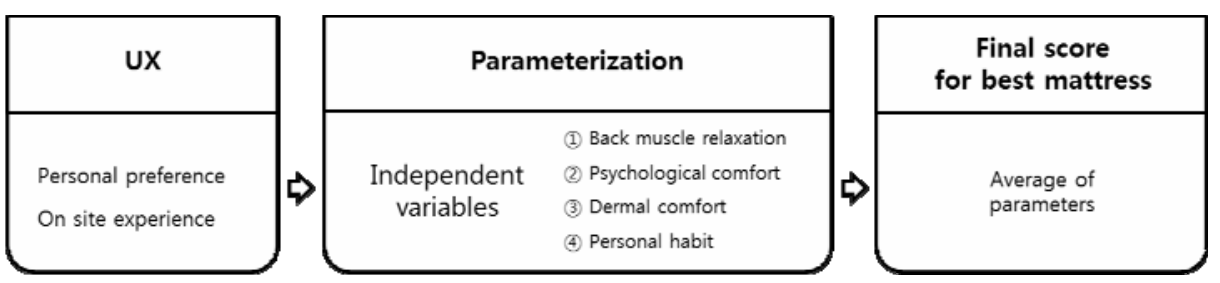

Fig. 1. Conceptual summary of methodology to measure the user experience with mattress

It is no need to argue that a good mattress can provide a good feeling of physical and psychological relaxation of the body when lying on it. Therefore, in this study, the back muscle relaxation, psychological comfort, cardiac efficiency, dermal comfort, and personal habit were measured by EMG, heart rate change, body pressure concentration, oxygen saturation level, and personal questionnaire. It is reasonable to say that those individual variables used in this study would evenly reflect the level of overall comfort. In order to express that, Body-Mattress Compatibility Score (BMCS) 
was suggested in this study as the average value of normalized score of individual variables. In addition to that, a regression analysis was performed to estimate the EMG value, which is difficult to be measured in the showroom. The final result with the estimated value was compared with subjective satisfaction score for validation. The Figure below shows the study flow (Fig. 2).

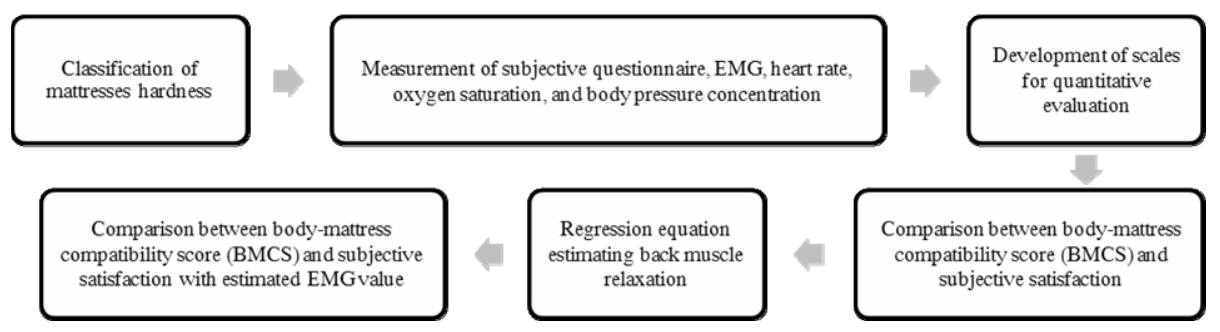

Fig. 2. Study flow-chart

\section{Classification of Mattress Hardness}

Five mattresses built with different hardness produced by "S" company were used for the present study. The hardness of the mattresses were measured by an endurance tester (KS-200B, Korea) by pushing the mattress material as much as $80 \mathrm{~mm}$. The difference in hardness was significant among five mattresses and showed in Table 1. The hardness was measured five times and five different spots per mattress.

Table 1. Result of paired t-test on mattresses with different hardness

\begin{tabular}{c|c|c|c|c|c}
\hline & mattress 1 & mattress 2 & mattress 3 & mattress 4 & mattress 5 \\
\hline mattress 1 & - & $.000^{* * * *}$ & $.000^{* * *}$ & $.000^{* * * *}$ & $.000^{* * *}$ \\
\hline mattress 2 & $.000^{* * *}$ & - & $.000^{* * *}$ & $.000^{* * * *}$ & $.002^{* * *}$ \\
\hline mattress 3 & $.000^{* * *}$ & $.000^{* * * *}$ & - & $.000^{* * * *}$ & $.000^{* * *}$ \\
\hline mattress 4 & $.000^{* * *}$ & $.000^{* * * *}$ & $.000^{* * *}$ & - & $.000^{* * *}$ \\
\hline mattress 5 & $.000^{* * *}$ & $.002^{* * *}$ & $.000^{* * *}$ & $.000^{* * *}$ & - \\
\hline
\end{tabular}

Depending on the result, we could confirm that the five mattresses could be classified into five levels based on the hardness. We defined that score 5 is the hardest and score 1 is the softest one.

\section{Measurement of Subjective Questionnaire, EMG, Heart Rate, Oxygen Saturation, and Body Pressure Concentration}

\subsection{Subjects}

An experiment was designed to measure the various bio-signals from ten male and ten

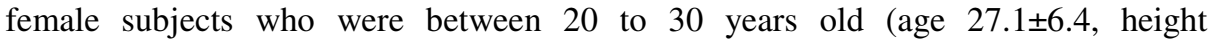
$167.1 \pm 7.2$, weight $66.2 \pm 18.4$ ). None of them had a medical history related to back pain (Table 2). 
Table 2. Information on participants

\begin{tabular}{rrrr}
\hline & Age & Height $(\mathrm{cm})$ & Weight $(\mathrm{kg})$ \\
\hline Average(SD) & $27.1(6.4)$ & $167.1(7.2)$ & $66.2(18.4)$ \\
\hline
\end{tabular}

\subsection{Experimental Design}

Five independent variables were the back muscle relaxation (EMG), psychological comfort (heart rate), dermal comfort (body pressure concentration), personal habit (personal questionnaire), and cardiac efficiency (oxygen saturation) (Table 3).

Table 3. Independent variables used to measure the comfort of the mattress

\begin{tabular}{|c|c|c|c|}
\hline $\begin{array}{c}\text { Measured } \\
\text { variables }\end{array}$ & Definition & & Formula \\
\hline $\begin{array}{l}\text { Back muscle } \\
\text { relaxation }\end{array}$ & $\begin{array}{l}\text { Decrement of muscle } \\
\text { activity before and } \\
\text { after using a mattress }\end{array}$ & Back muscle relaxation $_{\mathrm{i}}=$ & $\frac{\left.\mathrm{IEMG}_{i(l y i n g} 50 s \sim 60 s\right)}{\mathrm{IEMG}_{i(s \tan d i n g 50 s \sim 60 s)}}(i=1,2, \ldots, 20)$ \\
\hline $\begin{array}{l}\text { Psychological } \\
\text { comfort }\end{array}$ & $\begin{array}{l}\text { Decrement of heart } \\
\text { rate before and after } \\
\text { using a mattress }\end{array}$ & Psychological comfort $\mathrm{i}=$ & $\frac{\mathrm{HR}_{i(l y i n g 50 s \sim 60 s)}}{\mathrm{HR}_{i(\text { stan ding } 50 s \sim 60 s)}}(i=1,2, \ldots, 20)$ \\
\hline $\begin{array}{l}\text { Dermal com- } \\
\quad \text { fort }\end{array}$ & $\begin{array}{c}\text { The ratio of peak } \\
\text { pressure to mean } \\
\text { pressure when lying on } \\
\text { a mattress }\end{array}$ & Dermal comfort $_{i}=$ & $\frac{\mathrm{P}_{\text {averagei }}}{\left(\mathrm{P}_{1 s t \max i}+\mathrm{P}_{2 n d \max i}+\mathrm{P}_{3 r d \max i}\right) / 3}(i=1,2, \ldots, 20)$ \\
\hline $\begin{array}{l}\text { Personal } \\
\text { habit }\end{array}$ & $\begin{array}{l}\text { Likert score from } \\
\text { personal questionnaire }\end{array}$ & Personal habit $_{\mathrm{i}}=$ & $\frac{\mathrm{Q} 1_{\mathrm{i}}+\mathrm{Q} 2_{\mathrm{i}}+\mathrm{Q} 3_{\mathrm{i}}+\mathrm{Q} 4_{\mathrm{i}}}{4}(i=1,2, \ldots, 20)$ \\
\hline $\begin{array}{l}\text { Cardiac } \\
\text { efficiency }\end{array}$ & $\begin{array}{l}\text { Increment of oxygen } \\
\text { saturation in peripheral } \\
\text { vessels before and after } \\
\text { using a mattress }\end{array}$ & Cardiac efficiency $_{\mathrm{i}}=$ & $\frac{\mathrm{SaO}_{2 i(l y i n g 50 s \sim 60 s)}}{\mathrm{SaO}_{2 i(\text { stan ding } 50 s \sim 60 s)}}(i=1,2, \ldots, 20)$ \\
\hline
\end{tabular}

\subsection{Apparatus}

To measure back muscle relaxation, two EMG electrodes out of eight channel EMG system (ME-6000T, Mega Win, Kupio, Finland) were used to both left and right side of the erector spine. A pad $(190 \mathrm{~cm} \times 80 \mathrm{~cm})$ with $32 \times 32$ digital film sensors was used to measure the level of concentration of body pressure. Nihon Kohden Company's pulse oximeter was used to measure the heart rate and the oxygen saturation.

The questionnaire included 5 point scale questions about personal information, history of back pain, the preference on hardness of mattress in the past.

\subsection{Procedure}

Before the experiment, anthropometric data of subjects were measured, and a questionnaire was filled out. Then, the experiment process was explained and measuring device was attached to subjects and the stability of the signal was checked. EMG, heart rate and oxygen saturation signals were measured for 60 seconds while subjects were standing (baseline data) and lying (relaxation data) on the mattress. The data collected between 50 to 60 seconds, which was the most stable data, were used for data analysis. Also, the body pressure concentration was measured while subjects 
were lying on the mattress. Upon finishing the measurement, subjects were asked to lie down on other five mattresses one by one, and they recorded the level of subjective satisfaction in five Likert scale.

\section{Development of Scales for Quantitative Evaluation}

The normality of data of all variables was examined (Table 4). As results, the oxygen saturation $\left(\mathrm{SaO}_{2}\right)$ was excluded in evaluation process since it did not show a normal distribution.

Table 4. One-sample kolmogorov-smirnov for examination of normal distribution

\begin{tabular}{lccccc}
\hline & $\begin{array}{c}\text { Back muscle } \\
\text { relaxation }\end{array}$ & $\begin{array}{c}\text { Psychological } \\
\text { comfort }\end{array}$ & $\begin{array}{c}\text { Dermal } \\
\text { comfort }\end{array}$ & $\begin{array}{c}\text { Personal } \\
\text { habit }\end{array}$ & $\begin{array}{c}\text { Cardiac } \\
\text { efficiency }\end{array}$ \\
\hline $\mathrm{N}$ & 20 & 20 & 20 & 20 & 20 \\
\hline $\begin{array}{l}\text { Kolmogorov- } \\
\text { Smimov's Z }\end{array}$ & 0.694 & 0.722 & 0.422 & 0.909 & 1.790 \\
\hline $\begin{array}{l}\text { Approximate signifi- } \\
\begin{array}{l}\text { ance probability(two- } \\
\text { sided) }\end{array}\end{array}$ & 0.722 & 0.674 & 0.994 & 0.381 & $0.003^{* * *}$ \\
\hline $\begin{array}{l}\text { Normal distribu- } \\
\text { tion }(\text { Yes } / \mathrm{No})\end{array}$ & Yes & Yes & Yes & Yes & No \\
${\text { **** }<0.01, * * \mathrm{p}<0.05,{ }^{*} \mathrm{p}<0.1,}$ & & & & &
\end{tabular}

Table 5. Final scores of independent variables (raw score and normalized score in 5 point scale)

\begin{tabular}{c|c|c|c|c|c|c|c|c}
\hline & \multicolumn{2}{|c|}{$\begin{array}{c}\text { Back muscle } \\
\text { relaxation }\end{array}$} & \multicolumn{2}{c|}{$\begin{array}{c}\text { Psychological } \\
\text { comfort }\end{array}$} & \multicolumn{2}{c|}{ Dermal comfort } & \multicolumn{2}{c}{ Personal habit } \\
\cline { 2 - 9 } & Raw score & Nor. score & Raw score & Nor. score & Raw score & Nor. score & Raw score & Nor. score \\
\hline Sub1 & 1.24 & 2 & 0.68 & 5 & 4.50 & 3 & 3.0 & 3 \\
\hline Sub2 & 0.99 & 3 & 0.81 & 3 & 5.47 & 2 & 2.0 & 2 \\
\hline Sub3 & 0.70 & 4 & 0.80 & 3 & 5.91 & 1 & 2.8 & 3 \\
\hline Sub4 & 0.54 & 4 & 0.78 & 3 & 4.17 & 4 & 2.8 & 3 \\
\hline Sub5 & 0.70 & 4 & 0.75 & 4 & 5.08 & 2 & 2.8 & 3 \\
\hline Sub6 & 0.86 & 3 & 0.89 & 1 & 3.89 & 4 & 2.4 & 2 \\
\hline Sub7 & 0.67 & 4 & 0.95 & 1 & 4.16 & 4 & 3.2 & 3 \\
\hline Sub8 & 0.55 & 4 & 0.85 & 2 & 4.80 & 3 & 3.4 & 3 \\
\hline Sub9 & 0.47 & 5 & 0.81 & 3 & 3.45 & 5 & 3.2 & 3 \\
\hline Sub10 & 0.66 & 4 & 0.90 & 1 & 5.32 & 2 & 3.4 & 3 \\
\hline Sub11 & 0.56 & 4 & 0.72 & 5 & 4.73 & 3 & 3.0 & 3 \\
\hline Sub12 & 1.07 & 3 & 0.72 & 5 & 6.07 & 1 & 3.4 & 3 \\
\hline Sub13 & 0.40 & 5 & 0.87 & 2 & 3.15 & 5 & 2.4 & 2 \\
\hline Sub14 & 0.76 & 4 & 0.78 & 4 & 5.45 & 4 & 3.2 & 3 \\
\hline Sub15 & 0.74 & 4 & 0.88 & 2 & 3.99 & 4 & 2.8 & 3 \\
\hline Sub16 & 1.16 & 2 & 0.83 & 3 & 4.97 & 2 & 3.0 & 3 \\
\hline Sub17 & 1.64 & 1 & 0.80 & 3 & 5.90 & 1 & 2.6 & 3 \\
\hline Sub18 & 1.36 & 2 & 0.73 & 4 & 4.16 & 4 & 3.4 & 3 \\
\hline Sub19 & 0.87 & 3 & 0.82 & 3 & 3.81 & 4 & 3.2 & 3 \\
\hline Sub20 & 0.23 & 5 & 0.88 & 2 & 4.96 & 2 & 2.2 & 2 \\
\hline
\end{tabular}


Final variables used to develop a scale were the back muscle relaxation, psychological comfort, dermal comfort, and personal habit as shown in Table 5. Based on the maximum and minimum score of individual variable, 1 to 5 scale was used in the study. The Interval of the scale was determined as $\{($ maximum - minimum $) / 5\}$. Score 5 indicates that subject can relax on the mattress very well. Then, the hardest mattress can be recommended for biomechanical advantage to support low-back area. However, even the hardest mattress, which is currently in the market, has a substantial cushion on the top of it to make user feel comfortable (fig. 3). If the score is close to 1 , even softer mattress will be recommended for user feel more relaxed.
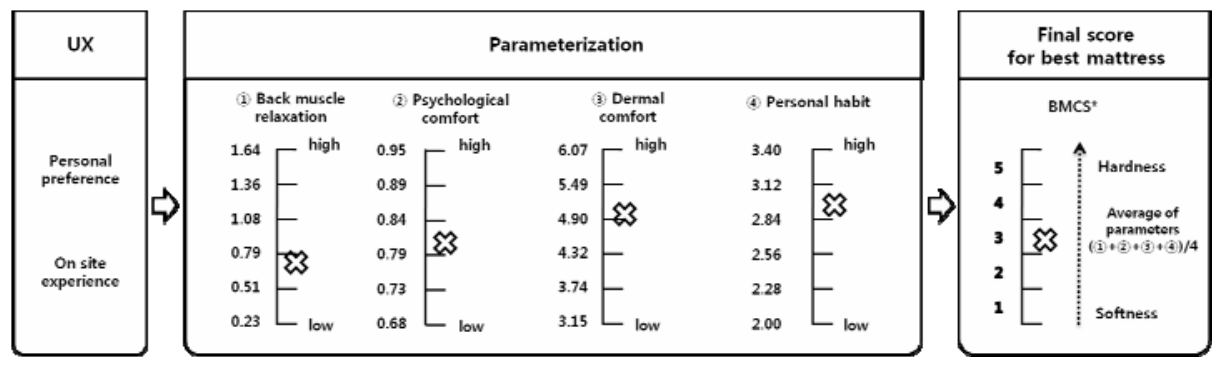

$* \mathrm{BMCS}=$ (normalized score of psychological comfort + normalized score of dermal comfort + normalized score of back muscle relaxation + normalized score of personal habit) / 4

Fig. 3. The scores and scales of individual variables, and body-mattress compatibility score (BMCS)

\section{Comparison between Body-mattress Compatibility Score (BMCS) and Subjective Satisfaction}

For validation of the BMCS, the score from subjective satisfaction was used. The comparison result is in Figure 4.

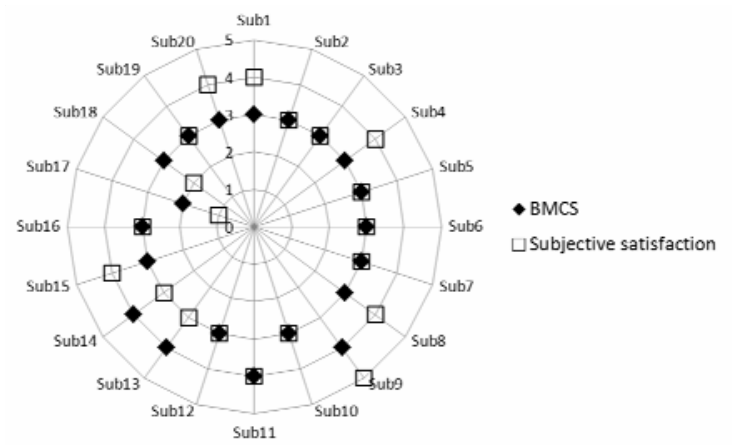

Fig. 4. Comparison between BMCS and subjective satisfaction scales 
BMCS and subjective satisfaction were matched each other among ten subjects. Among another ten subjects, BMCS and subjective satisfaction scales were found to be different only by one point.

\section{Regression Equation Estimating Back Muscle Relaxation}

Since it was difficult to use EMG equipment in showroom, an alternative method was investigated. By observing the spearman correlation coefficients table, the back muscle relaxation determined by measured EMG had meaningful relationship with other variables. Thus, a multiple regression analysis was conducted to investigate the possibility to estimate EMG value instead of actually measuring it.

Table 6. Correlation analysis with each variable

\begin{tabular}{ccccc}
\hline & $\begin{array}{c}\text { Back muscle } \\
\text { relaxation }\end{array}$ & $\begin{array}{c}\text { Psychological } \\
\text { comfort }\end{array}$ & $\begin{array}{c}\text { Dermal } \\
\text { comfort }\end{array}$ & $\begin{array}{c}\text { Personal } \\
\text { habit }\end{array}$ \\
\hline Back muscle relaxation & 1.000 & $0.580^{*}$ & $0.581^{*}$ & $0.520^{*}$ \\
Psychological comfort & $0.580^{*}$ & 1.000 & $0.653^{* *}$ & 0.349 \\
Dermal comfort & $0.581^{*}$ & $0.653^{* *}$ & 1.000 & 0.260 \\
Personal habit & $0.520^{*}$ & 0.349 & 0.260 & 1.000 \\
Oxygen saturation & 0.454 & 0.110 & 0.170 & 0.377 \\
\hline
\end{tabular}

In the regression model (equation 1) using three independent variables such as dermal comfort, psychological comfort and personal habit indicated $\mathrm{R}^{2}$ of 0.512 .

$$
\mathrm{Y}=2.077-0.003 \mathrm{X}_{1}+0.504 \mathrm{X}_{2}-0.178 \mathrm{X}_{3}
$$

Y: Back muscle relaxation

$\mathrm{IX}_{1}$ : Psychological comfort

$\mathrm{X}_{2}$ : Dermal comfort

$\mathrm{X}_{3}$ : Personal habit.

\section{Comparison between Body-mattress Compatibility Score (BMCS) and Subjective Satisfaction with Estimated EMG Value}

BMCS and subjective satisfaction were matched each other among ten subjects. Among another eight subjects, BMCS and subjective satisfaction scores were found to be different only by one point. Two subjects showed two points difference.

\section{Discussion}

The study has attempted to measure user experience in a very quantitative manner unlike many UX methods using mostly intuitive logics, although this study has intuitively adopted the idea that physical and psychological relaxation would be an important factor determining overall comfort of the mattress in the ideation process. We may say that user experience itself has multi-dimensional attributes that we cannot simply measure only through an experimental observation. However, it can be 
challenged when the behavioral pattern of the experience is simple and repetitive enough; and we have equipments and techniques to measure and analyze such human behavior.

In showroom situation, people buy products by using their own judgment based on their past and on site experience. However, we do not know whether or not buyers make the best decisions at all. Thus, it would be very reassuring for buyers if we could provide a methodology to help them guide or confirm their decisions by showing statistical results in ten minutes after interesting science experiment. Therefore, the methodology in this study can be considered as a useful tool for both merchandisers and customers in buying mattress.

In fact, we used four independent variables to cover various physical and psychological experiences of subjects, which induced the risk of mathematical fuzziness during the process of handling multiple variables with different dimensions. The measured values were transformed into normalized scores to have a unified value summarizing the results from the four final variables used in this study. In that process, it was also assumed that each variable had the same importance or same weight to determine the final result. In reality, this assumption may not be correct since people usually have their own preference or bias in reaching to their own final decision. So, this can create the insensitivity problem of the methodology if somebody's buying decision is made by one particular factor rather than the average of many different factors. This issue needs to be tackled in future study as we accumulate the field data to improve the sensitivity of the methodology.

For now, in order to confirm the validity of BMCS result, a subjective satisfaction was used in this study. Interestingly, there was no big difference between BMCS and subjective satisfaction score in selecting the final mattress. This validation process allowed us to use the methodology in the field without too much worry about producing conflicting outcome against buyer's preference. Statistically speaking, people tend to choose the mattress with medium hardness rather than extreme one. The methodology also guides customers to choose mattress based on the feedback from various psycho-physiological sensors, of which values were normally distributed. That is, we can expect that BMCS, that is the average of four scores from individual variables, is normally distributed and well depicts natural human behavior.

Another hidden device to prevent unreasonable outcome is in the questionnaire asking personal habit and previous experience about the mattress. There were two questions with the same content only with different wording. If a customer give different answers for the same questions, all the data from questionnaire is discarded to prevent biased outcome. This is probably the case when customer is not attentive or sincere enough in answering the question or not understanding the question. This process also helps us not having unreasonable recommendation.

The methodology introduced in this study was developed as a commercial system used in actual showroom. All the interfaces for easy operation of measuring process was designed and integrated as one complete system (Fig. 5). Visiting customers take approximately ten minutes to go through the test to get the final printed results. They experience an interesting science experiment which is very new and curious event for them, which actually help them to make a decision in buying the right mattress. In future, the validity and sensitivity of the methodology can be observed and analyzed based on empirical data collected from the field. Furthermore, a better mathematical approach can be investigated to improve the efficacy of the system. 

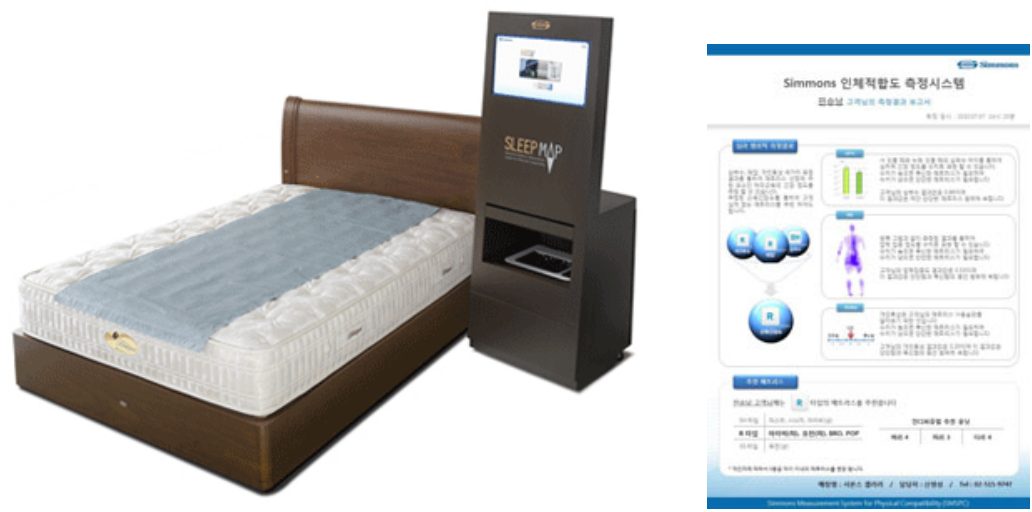

Fig. 5. The system set up in showroom and an example of printed result

\section{Conclusion}

We have shown that the user experience could be quantitatively measured for practical use in actual showroom. The methodology used in this study was designed for a particular product, but it could be applied to other products with a minor revision in various situations. The validity and sensitivity of the methodology can be further improved as we accumulate the field data and employ a more sophisticated device to integrate multi-dimensional information of human behavior in the near future.

\section{References}

1. Donaldson, E., Kennaway, D.J.: Effects of Temazepam on Sleep, Performance, and Rhythmic 6-sulphatoxymelatonin and Cortisol Excretion after Transmeridian Travel. Aviat Space Environ. Med. 62(7), 654-660 (1991)

2. Gaby, G.B., Sten, E.: The Influence of Bed Hardness on Sleep Quality. Applied Ergonomics 31, 487-497 (2000)

3. Kim, J.Y., Park, J.S., Yoo, S.W., Lee, S.J., Goh, T.S.: Ergonomic Test of Air-ball Mattresses Using Skin Pressure and Temperature Change. Proceeding of the Ergonomics Society of Korea 2(1), 283-287 (2007)

4. Kovacs, F.M., Abraira, V., Pena, A., Martin-Rodriguez, J.G., Sanchez-Vera, M., Ferrer, E., Ruano, D., Guillen, P., Gestoso, M., Muriel, A., Zamora, J., Gil del Real, M.T., Mufraggi, N.: Effect of Hardness of Mattress on Chronic Non-specific Low-back Pain: Randomised, Double-blind, Controlled, Multicentre Trial. Lancet 362, 1599-1604 (2003)

5. Lahm, R., Iaizzo, P.A.: Physiologic Responses during Rest on a Sleep System at Varied Degrees of Hardness in a Normal Population. Ergonomics 45(11), 798-815 (2002)

6. Parsons, H.M.: The Bedroom. Human Factors 14(5), 42-450 (1972)

7. Suckling, E.E., Koenig, E.H., Hoffman, B.F., Brooks, C.: The Physiological Effects of Sleeping on Hard or Soft Beds. Human Biology 29, 274-288 (1957) 
8. Vanderwee, K., Grypdonck, M., Defloor, T.: Alternating Pressure Air Mattresses as Prevention for Pressure Ulcers: A literature review. Age and Ageing 34(3), 261-267 (2005)

9. Yu, S.W., Kim, J.Y., Min, S.N., Sung, S.H.: Analysis of Suitability for Mattresses by Using Psycho-Physiological Measures. Proceeding of the Korean Society for Emotion \& Sensibility 19, 63-66 (2009)

10. Yu, S.W.: Analysis of Suitability for Mattresses by Using the Level of Physical Relaxation. master's thesis (2010) 